\title{
The Hidden Value of Water Flows: The Chemical Exergy of Rivers*
}

\author{
Antonio Valero, Javier Uche, Amaya Martínez ${ }^{* *}$ \\ CIRCE - University of Zaragoza, Zaragoza, Spain \\ amayamg@unizar.es
}

\begin{abstract}
The hydroelectrical potential of rivers is a very well-known parameter used to characterize the availability of a river as a function of its flow and its elevation. However, the chemical potential of water flowing through the rivers is commonly ignored. In its source, water presents high quality and, therefore, it owns an important availability that can be expressed through its chemical exergy value. On the opposite, when it flows into the sea and reaches the thermodynamic equilibrium, it cannot be further used and it is converted into a null exergy value. Within these two limit values, the exergy state of the river at its different stages can be assessed. On the other hand, water availability for specific uses depends on its quality. In this way, the almost always hidden value of water, its chemical potential, is highlighted and can be compared to the potential component, since they are expressed in the same units (energy units). In this paper, it is shown that potential and chemical exergy values of rivers rise to values of the same order of magnitude. That is, the chemical value of a river is, from a thermodynamic perspective, as much as its potential value. The main difference lies in the current available technologies to take advantage of their physical disequilibrium: while hydro-power turbines are a completely proven technology, there is only one experimental plant and not yet commercial devices to take advantage of the hydro-chemical potential. This fact is also considered attending to the biological advantage that is effectively taken from ecosystems due to the chemical disequilibrium between the river and the seawater, and to the environmental conflict that such potential devices could imply. Results of the estimations for a small Spanish river, the Muga river, are presented in this paper in order to prove the accuracy of the methodology. It is shown that the potential exergy of that river ranges from 2.37 to $7.15 \mathrm{MW}$, while its chemical exergy is comprised between 2.30 and $8.78 \mathrm{MW}$ for the present state of the river. In addition, several exergy indexes are defined as basic parameters to provide information about the advantage taken from the river, that is, about the water uses within the watershed.
\end{abstract}

Keywords: Exergy of water; chemical exergy; water potential.

\section{Introduction}

The energy of moving water has been used for thousands of years to power flour mills and irrigation systems. Water wheels were set within a flowing river, and the rotation generated movement was transformed into shaft work. In fact, water was the primary energy source for industrial applications during the $19^{\text {th }}$ Century, when mill buildings appeared along the rivers throughout Europe and the United States (Delli, 2000).

This way of producing electricity has been improved over the years and it is nowadays a well proven technology despite its inconvenient consequences such as those associated with the construction of reservoirs.

Hydroelectric power is then one of the oldest power generation methods and a critical part of world power generation $(15 \%$ of the share of world global electricity WEC 2007). It is expected to continue expanding due to its non-reliance on fossil fuels, especially in developing countries with high potential.

The operating costs of hydro-power utilities represent only a small fraction of the initial capital cost. Hydroelectricity is a compelling partner to ensure security in mixed power systems as well and the multi-purpose reservoirs can be associated to security of water supply as well as power (WEC, 2007). As far as hydropower resources are concerned, the International Hydropower Association, IHA (IHA, 2008), estimates that only onethird of the realistic potential has been developed.

Just like mass flows spontaneously from a position of high gravitational potential to a position of low gravitational potential, it is also well-known that matter flows from a region of high chemical potential to a region of low chemical potential. The chemical potential can therefore be used to determine whether or not a system is in equilibrium. That chemical imbalance in the river streams flowing to the sea is pointed out in this paper. If our technology were able to take advantage of the available energy coming from the chemical potential of water, an important amount of energy could be obtained.

The associated physical phenomenon is the osmosis effect. As is well known, it is the net movement of water across a selectively permeable membrane driven by a difference in osmotic pressure across the membrane. Present-day applications of the osmosis phenomenon extend from water treatment and food processing to power generation and novel methods for controlled drug release (Cath et al., 2006). In the field of water treatment, reverse osmosis is a mature process as compared with osmosis. 
Osmosis is also named as forward osmosis (FO) or direct osmosis. This phenomenon has been used at benchscale to treat industrial wastewaters and to treat liquid foods in the food industry; and to concentrate landfill leachate at pilot- and full-scale. FO is also being evaluated for reclaiming wastewater for potable reuse in life support systems (at demonstration-scale), for desalting seawater, and for purifying water in emergency relief situations (Cath et al., 2006). Recent developments in materials science have also allowed the use of FO in controlled drug release in the body. Nevertheless, there are few publications in literature on the use of osmosis for water treatment and/or engineering applications. In any case, the reported initiatives regarding the state of the art of the FO make clear that it is still an immature technology when the attention is focused on a large scale, that is, for instance, on taking advantage of the chemical potential of rivers.

The first large scale osmosis power plant went on stream in Oslo fjord in southern Norway in 2009 (New Scientist, 2011). There, as explained, sea and fresh water are separated by a membrane. The seawater draws the fresh water through the membrane, thereby increasing the pressure on the seawater side. The increased pressure is used to produce power. According to the company in charge, a full-scale commercial osmotic power plant could be ready by 2015 (NES, 2011).

In order to assess such a chemical value, our proposal is to include the quality and degradation aspects in the analysis of water bodies. A river is something further from elevation and flow. It is the core of the fluvial ecosystem that embodies life and it chemical composition and chemical potential are therefore a fundamental aspect in its characterization.

From a physical perspective, this means to include the second law of thermodynamics (Valero et al., 2009), i.e. exergy as the working tool.

\section{Fundamentals}

Many authors have contributed to the development of exergy and thermoeconomic accounting, completing the existing theories and even opening new research lines (Szargut et al., 1998; Valero, 1998; Wall, 1986; Jorgensen, 2006; Gong and Wall, 2001; Chen, 2006; Chen and Ji, 2007; Valero et al., 1986; Zaleta et al., 1998). As it is well known, the exergy balance accounts for the degradation of energy. Eq. (1) quantifies the irreversibilities of a process as the difference between the exergy of the input and the output flows.

$$
B_{\text {input }}-B_{\text {output }}=\sum I
$$

Within thermoeconomics, each flow or some purposive combination of flows are identified either as fuel, product or residues (waste). Then Eq. (1) becomes for pro-exergy devices, those whose aim is to increase the exergy of the product(s):

$$
F-P=R+I>0
$$

And, for anti-exergy devices, those whose aim is to deliberately decrease the exergy of the residues/wastes:

$$
R+F_{R}=I_{R}
$$

where $F_{R}$ is the additional fuel needed to get rid of the residue/waste and $I_{R}$ the additional irreversibility caused for such an abatement. Equations (2) and (3) are of utmost importance because they place purpose in the heart of thermodynamics. The desire to produce a certain product is external to the system, and must be defined beforehand.

The pro and anti-exergy processes denomination is heir to the nomenclature already introduced by Le Goff in 1979 as a result of his thermodynamic interpretation of the nature of each considered process (Le Goff, 1979).

As exergy is an additive property, not all the exergy in a given physical flow must be considered either a product or a waste. For instance, when we drink water, heat and poisonous substances must be removed. However heat and wastes increase the exergy of water. Then waste waters carry two types of components, those to get rid of and those making water useful for some purpose.

In addition, the analogy between the availability of a natural resource and its exergy helps us to relate each resource parameter with its physical and chemical exergy components as explained in Section 3.

Exergoecology is defined as the application of the second law of thermodynamics for the assessment of natural fluxes and resources on the Earth (Valero, 1998). The consumption of natural resources implies destruction of organized systems and dispersion, which is in fact generation of entropy or exergy destruction. This is why the exergy analysis can describe perfectly the depletion of natural capital and, specifically, the degradation of water bodies.

We now apply these ideas to a watershed facing two different boundary systems:

i) Water-related technology plants

ii) The whole river.

\subsection{Water plant approach}

First, the water-related plants operating in the river basin can be studied. The eventual type of technologies would be:

2.1.1) Potential exergy device or conventional Dam. Where the potential energy of water is converted into electricity.

\subsection{2) Chemical exergy device (CED).}

Although this kind of power plants do not currently exist on a large full-commercial scale they will be based on forward osmosis phenomena. The recent news from the plant operating in Norway (NES, 2011) opens exciting and stimulant perspectives.

Both devices could be represented by the general schema shown in Fig. 1 and analyzed according to Eq. (4), where it can be identified the exergy as fuel in the input (i) and output points (o), the obtained product (P) and the irreversibility of the process (I). It is directly obtained from Eq. (2).

$$
F_{i}-F_{o}=P+I
$$

2.1.3) Waste water treatment plant (WWTP). They are located close to the water use areas and they are the most common quality-restoration technologies in any watershed. 


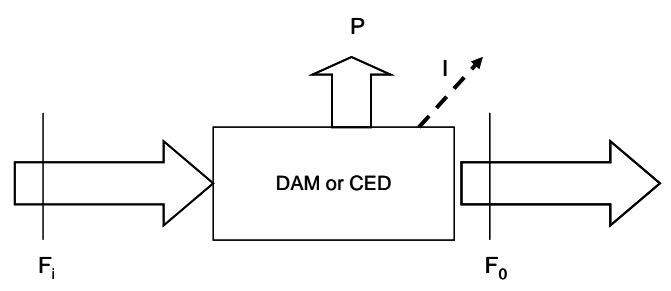

Figure 1. Dam or CED diagram.

Before representing the plant diagram, as in the two previous technologies, it may be convenient to state that, from the previous analysis, any water flow can be interpreted as an exergy flow carrying some valuable exergy, the product $\mathrm{P}$, and some exergy that needs to be eliminated, the residue $\mathrm{R}$. The stated final objective in a WWTP would be then eliminating that R. To achieve the final state, external exergy sources need to be implemented. $F_{R}$ represents the clean-up expended exergy used for producing quality water. In particular, the idea can be summarized as Figure 2 indicates. Each part of the water flow, the product $\mathrm{P}$ and the waste $\mathrm{R}$, can be characterized by it chemical exergy, which is separately given for its inorganic matter and organic matter components. This separation is commonly used in Physical Hydronomics (Valero et al., 2009), since the measures to restore them are different.

\begin{tabular}{cl}
\hline$P$ & $b_{\text {IM,OS }}$ \\
& $b_{O M, O S}$ \\
\hline$R$ & $b_{\text {IM,OS-PS }}$ \\
& $b_{\text {OM,OS-PS }}$ \\
\hline
\end{tabular}

Figure 2. Water stream as an exergy flow.

The exergy of the product is defined by the exergy in the objective or aimed state of the river (OS) in a given location. However, in order to reach such a state, the waste $\mathrm{R}$ (accounting for the difference between the present state, PS, and the OS) has to be eliminated.

The waste $\mathrm{R}$ may show a negative or a positive value depending on the considered parameter, but it does not affect the concept of being a residue that needs to be eliminated from the water flow. Note that according to the defined RE (seawater without organic matter), eliminating organic matter from the water flow means reducing its exergy. However, to remove inorganic matter means an increase of the exergy content of water.

The irreversibility in the system is then given by the waste and the exergy needed for eliminating it (Eq. 3). In the considered water flow, a part of the residues to be eliminated is organic matter, OM, mainly coming from the urban domestic uses, and the other one is inorganic matter, IM, accounting for the excess of different salts (Eq. 5).

$R_{O M}+R_{I M}+F_{R, O M}+F_{R, I M}=I_{R}$
In consequence, the simplified diagram of a WWTP is shown in Fig. 3. The irreversibility $\mathrm{I}$ and the residue $\mathrm{R}$ $\left(\mathrm{R}_{\mathrm{OM}}+\mathrm{R}_{\mathrm{IM}}\right)$ comprise the $\mathrm{I}_{\mathrm{R}}$ term in Eq. (5).

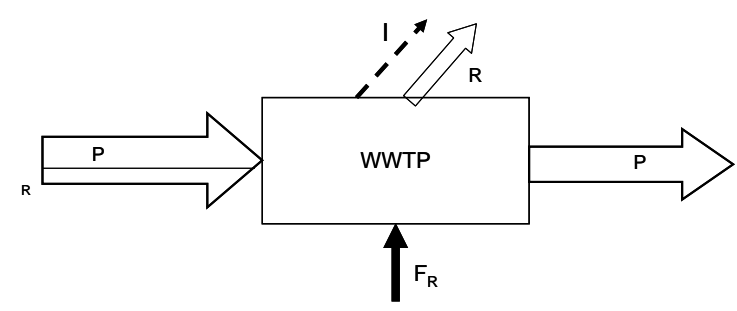

Fig. 3. WWTP diagram.

An index related to this dissipative process can be defined as the ratio between the residues and the fuel used to eliminate that waste (Eq. 6). It is named as the Residues in the Treatment Plant Index (RTPI). This is in fact the most representative parameter in waste water treatment plants since depuration of $\mathrm{OM}$ is the object of these plants.

$R T P I=-\frac{R}{F_{R}}$

The value of this index in the studied cases is, in general, lower than one because of the amount of exergy required to clean the river. However, its theoretical limit value is infinite when the river was restored without using any external exergy source.

The same analysis applies to a desalination plant considered as a fresh water source. In particular, specific membrane devices may be accounted for in the analysis of the tertiary treatment process of some WWTP or in brackish water handlings.

\subsection{Whole river approach}

By making wider the boundaries of the system the whole river can be studied from an exergy perspective. Two approaches are considered: the productive (proexergy) approach and the dissipative (anti-exergy) one.

2.2.1) Pro-exergy river approach. The river can be seen as a fuel $\left(\mathrm{F}_{\mathrm{pot}}\right.$ and $\left.\mathrm{F}_{\text {chem }}\right)$ flowing to the sea from which different products $\left(\mathrm{P}_{\text {pot }}\right.$ and $\left.\mathrm{P}_{\text {chem }}\right)$ can be obtained. Within the basin, several dams ( $\Sigma$ Dam) and chemical exergy devices ( $\Sigma$ CED) may exist. The conceptual diagram is shown in Fig. 4.

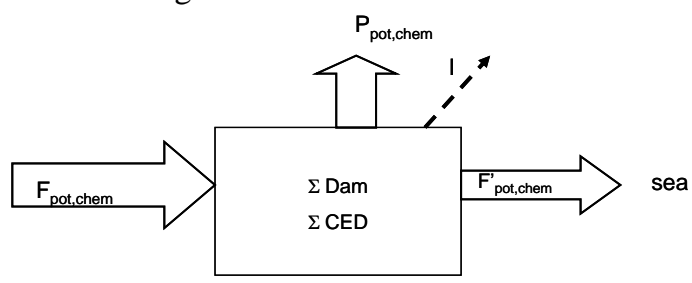

Fig. 4. Productive (pro-exergy) overall vision of the river.

Going further in this idea, two new indexes may be defined: The index of Potential Use of the River (PURI, Eq. 7) and, the index of Chemical Use of the River (CURI, Eq. 8). They can be both understood as indexes of the productive process naturally related to water. 


$$
P U R I=\frac{P_{p o t}}{F_{p o t}}
$$

where $\mathrm{P}_{\text {pot }}$ represents the energy obtained from the facilities along the river course, in $\mathrm{MWh} / \mathrm{yr}$, and $\mathrm{F}_{\text {pot }}$ stands for the existing potential in the watershed (potential exergy component of a water flow) due to the height differences. Conventionally it is named as the gross theoretical capability of hydropower in the watershed. This index, therefore, gives an idea about how much of the height potential is being used and its maximum value is one.

In parallel to the potential coming from the elevation, the chemical potential is relevant as well.

$$
C U R I=\frac{P_{c h}}{F_{c h}}
$$

where $\mathrm{P}_{\mathrm{ch}}$ would be the energy obtained from the facilities using the chemical potential of the water and $F_{c h}$ stands for the existing potential in the watershed. Currently, apart from the Norwegian exception and some other experimental facilities, there is not any utility able to take advantage of the chemical exergy of the river at large scale and, in consequence, $\mathrm{P}_{\mathrm{ch}}$ is equal to zero in any river. Then, the chemical use index of rivers is, at the current technology state, null.

It is worth to highlight that due to the existence of dams along the river flow, sediments are retained and in consequence the biological quality of the river is affected. Therefore, both PURI and CURI indexes are related. Note also that $P_{c h}$ and $F_{c h}$ are of incremental nature since the chemical exergy may increase or decrease along the river.

2.2.2) Anti-exergy river approach. Here, all the WWTPs contributing to the maintenance of the river with an adequate quality are accounted for. The required exergy to operate all of them $\left(\Sigma F_{R}\right)$ is compared to the chemical exergy of the river, given by $\mathrm{F}_{\mathrm{ch}}$. The considered flows are schematized in Fig. 5.

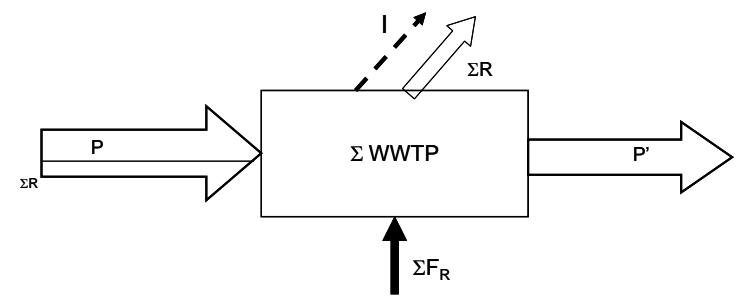

Fig. 5. Dissipative (anti-exergy) overall vision of the river.

A third index can be additionally defined in order to obtain information about the fuel consumed to keep clean the whole river waters $\left(F_{R}\right)$, in relation to the overall chemical potential in the river $\left(\mathrm{F}_{\mathrm{ch}}\right)$. That is the fuelresidues river index $\left(\mathrm{F}_{\mathrm{R}} \mathrm{RI}\right)$, as Eq. 9 indicates.

$$
F_{R} R I=\frac{F_{R}}{F_{c h}}
$$

The analysis of this index is very interesting, since it allows the comparison between the exergy that could be potentially obtained from the chemical disequilibrium in the river $\left(\mathrm{F}_{\mathrm{ch}}\right)$ and the exergy that is currently being invested to return the water flow with a good enough quality $\left(\mathrm{F}_{\mathrm{R}}\right)$. It could happen that more resources were needed to maintain water with the required quality than the real exergy contained in the stream.

\section{Exergy Formulas}

Consuming a natural resource requires some previous chemical and physical treatments (e.g., for human consumption, water must be extracted from a river or sea, must be purified and finally sent to end users). The exergy of a system gives an idea of its potential for not being in thermodynamic equilibrium with the Reference Environment, RE. This RE must be chosen as reasonably similar to the actual environmental conditions as possible.

The most important features of the exergy components of water have been studied in the literature (Valero et al., 2009; Chen and Ji, 2007; Zaleta et al., 1998). Potential, chemical and, in some cases, thermal components are concluded to be the most relevant parameters to be studied in general water bodies analyses, which makes them differ from the surroundings.

The proposed assessment methodology starts with a deep knowledge of the watershed. First, a set of gauging stations and chemical measurements are identified and filtered with the final target of getting measures of flow and quality coinciding in space and time. Since they do not generally cover the whole river area, simulation software is implemented to complete the input data for the exergy calculations. Afterwards, from the exergy values along the water flow, the exergy profile of the river is obtained by integrating the exergy values along the course, according to Eq. (10) and Eq. (11). These calculations are developed separately for each of the exergy components because of their different nature and order of magnitude.

Finally, the comparison of the physical exergy values of the river with those real values being used within the basin is carried out through the defined indexes.

$$
\begin{aligned}
& B_{p}=\int g Q(h) d h \approx g \sum_{i}(Q(h) \cdot \Delta h)_{i} \\
& B_{c h}=\int Q(b) d b \approx \sum_{i}(Q(b) \cdot \Delta b)_{i}
\end{aligned}
$$

The potential and chemical value of the river could only be calculated after simulating the whole stream. Sampling and gauging stations and rainfall together with the hydromorphological features of the river, the corresponding tributaries, catchment and returns were considered. Natural and anthropic located and diffuse pollution were considered as well. Finally, a set of river stretches were perfectly defined to perform the analysis.

Theoretically, flow increases as the river runs to its mouth, although catchments mean important variations. The chemical exergy component changes because of the pollutants, but the existence of WWTP in urban areas are especially relevant to maintain the river quality.

\subsection{Exergy value of a water flow}

The exergy value of a water body has, in general, five components: thermal, mechanical, chemical, kinetic and potential (Zaleta et al., 1998). As already said we have 
two main basic components: its composition (chemical exergy), which makes it useful for different urban, industrial and agricultural uses, and its elevation (potential exergy), that can be used to produce shaft work and electricity.

Therefore, and starting from these components, it is possible to evaluate in quantitative (flow, Q) and qualitative (specific exergy, b) terms a water body and any water resource characterised by its exergy components. The proposed model considers temperature, pressure, height, velocity, concentration and composition. The model assumes the approximation to an incompressible liquid (Martínez and Uche, 2010).

$$
\begin{aligned}
& \underbrace{b_{H_{2} O}(k J / k g)}_{\text {Total.specific.exergy, } b}=\underbrace{c_{p, H_{2} 0}\left[T-T_{0}-T_{0} \ln \left(\frac{T}{T_{0}}\right)\right]}_{\text {Thermal.Ex }, b_{t}} \\
& +\underbrace{v_{H_{2} O}\left(p-p_{0}\right)}_{\text {Mechanical.Ex, } b_{\text {meh }}}+\underbrace{\left[\sum_{i} y_{i}\left(\Delta G_{f_{i}}+\sum_{e} n_{e} b_{c h, n_{e}}\right)_{i}\right]_{p}}_{\text {Chemical.Ex, } b_{\text {ch, },}} \\
& +\underbrace{R T_{0} \sum_{i} x_{i} \ln \frac{a_{i}}{a_{0}}}_{\text {Concentration.Ex, } b_{\text {ch }, f}}+\underbrace{\frac{1}{2}\left(\frac{C^{2}-C_{0}^{2}}{1000}\right)}_{\text {Kinetic.Ex }, b_{k}}+\underbrace{g\left(h-h_{0}\right)}_{\text {Potential.Ex }, b_{p}}
\end{aligned}
$$

where subindex $o$ denotes the water properties of the reference; $c_{p}$ stands for the specific heat at constant pressure; $\mathrm{y}_{\mathrm{i}}$ represents the moles of the substance $i$ divided by the total mass of the dissolution (it can be assumed equal to the molality); $\Delta G_{f}$ is the Gibbs free energy; $n_{e}$ is the moles number of the elements (e) forming a compound (i) and $b_{c h, n e}$ its corresponding specific chemical exergy; $x_{\mathrm{i}}$ is the molar fraction and $a$ is the activity.

Each component in Eq. (12) should be separately calculated. The sum of all components expresses the exergy of the given water resource and can be understood as the minimum energy required to restore the resource from its RE.

The reference environment for this analysis is, clearly, the ocean. An idealized ocean without organic matter and the typical salts composition of the corresponding seawater is considered as the reference state for the natural water cycle. Its main features are elevation equal to zero and chemical composition equal to the average oceans inorganic composition. Then, when a water flow reaches its mouth after being used, and mixes into the seawater, it has zero chemical exergy as well. Additionally, this means that a significant loss of exergy occurs by mixing river and seawaters in the river mouth.

In other words, it could be said that the exergy in the source and in the mouth of the river is null. From the general expression of the total exergy as product of the flow times the specific exergy, it can be easily understood the null value from the null flow at the spring, and also the exergy equal to zero when it mixed with the ocean. However, that statement has to be correctly understood, keeping in mind the importance of the nutrients that the river provides to its mouth area. Such contribution is fundamental for the maintenance of the biological life in the area. In this sense, the null value of the chemical exergy is achieved some kilometres far from the coast, when the equilibrium with the ocean water has been reached.

Only the two mentioned and more representative exergy components of water are commonly considered for fresh water analyses: chemical quality and geopotential (Botero, 2000). The first one is the minimum energy needed to return the quality characteristics to water and could be obtained by desalination and depuration techniques. The second one is the minimum energy needed to return the resource to its condition of potential disequilibrium as delivered by the hydrological cycle. In the following, a brief description and practical considerations of those exergy components is provided.

\subsubsection{Potential exergy component}

As it is well-known, the potential exergy term -Eq. (13)- is calculated from the height $z$ (m) where the measurement is taken. Q stands for the flow, $g$ represents the gravitational acceleration of the Earth $\left(9.81 \mathrm{~m} / \mathrm{s}^{2}\right)$ and $\mathrm{z}$ the elevation $\left(\mathrm{z}_{0}=0\right.$ at sea level $)$.

$B_{p}=Q \cdot g\left(z-z_{0}\right)$

Although this term is quite important in the river source of a basin, it should be considered with special attention for the case of reservoirs with installed hydropower utilities: this potential exergy will be converted successively into kinetic, mechanical and electrical energy within the power station.

No matter the disaggregation level, this potential component will be present in any water analysis related to energy. It can be calculated from the flow and elevation figures, but there is also a different alternative to obtain the potential exergy component of a river. It is suggested from the point of view of the second law of thermodynamics: the minimum energy to elevate water (potential exergy) coincides with the maximum energy obtained when it is turbinated using a reversible machine. Therefore, available figures from the inventory of the world's hydropower capacity can be used to calculate the minimum energy required for pumping (or restoring potential exergy component).

Hydropower generation is measured on a large scale in TWh/year and different associated parameters are defined. The gross theoretical capability (GTC) expresses the total amount of electricity which could potentially be generated, if all available water resources were turned to this use. Those figures are estimated on the basis of atmospheric precipitation and water run-off. The technically exploitable capability (TEC) means the hydropower capability which is attractive and readily available with existing technology. The economically exploitable capability (EEC) is that amount of hydropower generating capacity which could be built, after carrying out a feasibility study on each site at current prices, and producing a positive outcome (WEC, 2007).

\subsubsection{Chemical exergy component}

The intrinsic chemical exergy of any element is easily found in any chemical exergy table [6] and its expression is given in the $b_{c h, f}$ component in Eq. (14). In addition to the chemical exergy, the concentration of the substance in the water body has to be compared with its concentration in the RE. This term, defined by the second part of Eq. 
(14), $b_{c h, c}$, is the most complex term to calculate since three different contributions have to be considered: the concentration of pure water and the contributions corresponding to the dissolved inorganic and organic substances.

$$
\begin{aligned}
B_{c h} & =Q \cdot\left(b_{c h, f}+b_{c h, c}\right) \\
& =Q \cdot\left[\sum_{i} y_{i}\left(\Delta G_{f_{i}}+\sum_{e} n_{e} b_{c h, n_{e}}\right)+R T_{0} \sum x_{i} \ln \frac{a_{i}}{a_{0}}\right]
\end{aligned}
$$

where $\Delta G_{f}$ is the formation Gibbs energy, $\mathrm{n}_{\mathrm{e}}$ is the amount of kmol of the element e and $b_{\text {chne }}$ is the standard chemical exergy of the element. This component gives an idea about the energy required to form a molecule from the existing substances in the RE. If the molecule takes part of the RE, its formation exergy component is equal to zero (since it already exists in that RE). $x_{i}$ is the molar concentration and $a_{i}$ is the activity coefficient of substance $i$ on water. Activities are rather used than molar concentrations, since we are dealing with solutions.

Attending to the chosen RE (an idealized seawater with average salts composition and without any organic matter), it is important to analyze how the chemical exergy component is going to be obtained. The IM chemical component will be assessed by calculating the second component in Eq. (14). The chemical exergy coming from the OM, however, will be calculated with the first term in Eq. (14), where the formation energy is accounted for.

Once the tool to assess the value of a river has been explained, the attention is focused on the river to be analyzed.

Exergoecology has been repeatedly applied during the last years to calculate the degradation costs of water bodies due to the anthropogenic presence. Special attention has been devoted to the comparison of the exergy difference between two given states of the river. Such a difference is obtained through the total exergy profiles of water courses under present or any other objective conditions. Each river exergy profile represents one of the statuses of the river.

In particular, several works related to the European Water Framework Directive (WFD) implementation through the branch of exergoecology called Physical Hydronomics have been published by the authors (Valero et al, 2009; Martínez et al., 2010).

Physical Hydronomics is the specific application of thermodynamics to physically characterize the degradation and modification of water bodies; i.e. the physical application to the European Water Framework Directive. The final objective of $\mathrm{PH}$ is to use those calculated physical costs as a guide to allocate the environmental and resource costs proposed by the WFD.

In this paper, some of the river states defined by the $\mathrm{PH}$ are going to be used to illustrate the starting hypothesis: the huge importance of the chemical potential of rivers. These river profiles are the present state (PS), the objective state (OS) and the natural state (NS) of the river. The former is understood as current state of the river, defined by its pressures and natural conditions. The OS comes from the objectives established by the WFD regarding to the required state of the rivers by 2015 (in flow and quality) according to the type of river or water mass that is being considered. Finally, the NS of the river is characterized as if the water stream were unaffected by any anthropogenic presence.

In general and in addition to the collected data from gauging and quality sampling stations, river simulation software is required to obtain detailed information (quantity and quality values) of the river in space and time. Additionally, the responsible official organism should provide information regarding the natural state of the rivers and the objective state of each stretch of the river defined by 2015 according to the legislation.

\section{Case Study}

The methodology can be carried out for any water body. It is only after studying the obtained figures when the theoretical hypothesis takes shape and the scope of the ideas can be tested. The proposed methodology to highlight the relevance of the chemical component of rivers is going to be applied in this section to a Spanish river basin. The Muga Watershed (Figure 6) is located in the 1'Alt Empordà region, northeast Catalonia, in eastern Spain. Its surface is $758 \mathrm{~km}^{2}$ (2.3\% of Catalonia), with an average annual rainfall of $612 \mathrm{hm}^{3}(807 \mathrm{~mm})$ and an average yearly contribution under natural regime conditions of $147.76 \mathrm{hm}^{3}$ (CWA, 2004). There are 34 villages in the watershed area and the population rises to 65,756 inhabitants.

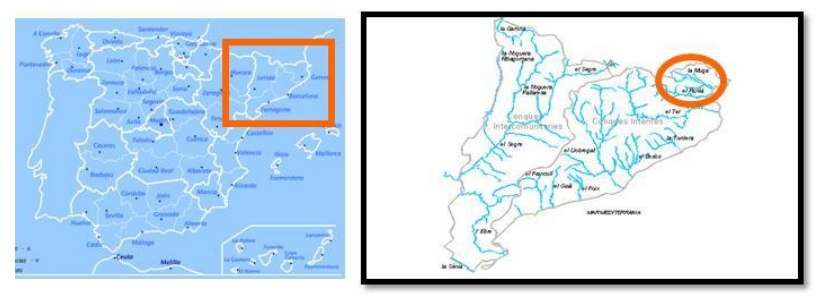

Figure 6. Calatonia in Spain and La Muga Basin within Catalonia.

The Muga river is born in the Pyrenees and it flows along $65 \mathrm{~km}$ until its mouth close to the Natural Park Aiguamolls de l'Empordà (Ventura et al., 2000). The upper stretch of the Muga river, upstream of the Boadella reservoir, flows through a mountainous area where several particular spurious irrigation lands are located (CWA, 2008).

The dam is devoted to supply water to the city of Figueres and to irrigate wide agricultural lands downstream. It has also permission for nautical sailing activities. In the dam there is also a hydroelectric power plant (3.6 MW). Hydropower generation is subordinated to the irrigation demands, that is, only the water flowing to irrigation canals is turbinated. So, Figueres supply catchment and the maintenance flows are independent from the central derivation and those flows are not turbinated. Downstream from the dam there is a canal to regulate the drainage from the hydropower and, in this way, to be able to favour the plant operation: when the irrigation demand decreases, a water volume higher than the demand is turbinated and regulated in that canal.

The river dies in the Mediterranean Sea, whose average composition has been considered as RE to carry out the exergy calculations. 


\subsection{Results. Exergy Value of La Muga River.}

The potential content of water is commonly used in hydroelectricity issues, what leads to the PURI index definition. Nowadays, the chemical content of the river is not used to produce energy and, as a result, the CURI index is zero at the current state of technology. In addition, two additional indexes related to the fuel used to maintain clean the river waters are defined (see Section 2.1).

At this point, it is worth to remember that the chemical potential is defined by the exergy of water $b_{\mathrm{H} 2 \mathrm{O}}$. This value generally appears aggregated with the $b_{\text {salts }}$ in the term $b_{\mathrm{IM}}$. Because of the small value of the salts exergy, $b_{\mathrm{H} 2 \mathrm{O}}$ and $\mathrm{b}_{\mathrm{IM}}$ are similar (Table 1). However, the salts contribution is fundamental because the increase of salts dissolved in the river water indicates a decrease in the water exergy value.

Table 1. Comparison of $B_{H 2 O}$ and $B_{I M}$ for the PS, OS and NS in the Muga river.

\begin{tabular}{|c|c|c|}
\hline \multicolumn{3}{|c|}{$\mathrm{B}_{\mathrm{H} 2 \mathrm{O}}(\mathrm{MW})$} \\
\hline & Min & $\operatorname{Max}$ \\
\hline PS & 2.30 & 8.78 \\
\hline OS & 2.62 & 9.71 \\
\hline $\mathrm{NS}$ & 2.51 & 9.40 \\
\hline
\end{tabular}

$\mathrm{B}_{\text {chem }}(\mathrm{MW})$
\begin{tabular}{|c|c|c|}
\hline & Min & Max \\
\hline \hline PS & 2.30 & 8.78 \\
\hline OS & 2.36 & 8.85 \\
\hline NS & 2.38 & 8.91 \\
\hline
\end{tabular}

Table 2 summarizes the results obtained for the potential and the IM component. The study was carried out for each month in an average year. Here, for the sake of clarity, only the values range (minimum and maximum) have been reproduced.

Table 2. Minimum and maximum exergy values of the Muga river.

$\mathrm{B}_{\text {pot }}(\mathrm{MW})$
\begin{tabular}{||c|c|c|}
\hline & Min & Max \\
\hline \hline PS & 2.37 & 7.15 \\
\hline OS & 2.44 & 7.16 \\
\hline NS & 2.64 & 8.05 \\
\hline
\end{tabular}

$\mathrm{B}_{\text {chem }}(\mathrm{MW})$
\begin{tabular}{|c|c||c|}
\hline & Min & Max \\
\hline \hline PS & 2.30 & 8.78 \\
\hline OS & 2.36 & 8.85 \\
\hline NS & 2.38 & 8.91 \\
\hline
\end{tabular}

The maximum chemical exergy value of water is, as expected, obtained for the Natural State of the river and rises up until 8.91 MW. Since the elevation is constant, independently of the considered state of the river, this value is determined by the flow and the flow in the natural state of the river is in general the highest one.

Table 3 summarizes the average exergy values for the Muga watershed. As it can be seen, the order of magnitude of the 'pot' and IM components is the same. The potential of the NS of the river is higher than the potential in the PS and in the OS.

Table 3. Average exergy values of the Muga river

\begin{tabular}{||c||c||c||}
\hline \hline & $\begin{array}{c}\mathrm{B}_{\text {av,pot }} \\
(\mathrm{MW})\end{array}$ & $\begin{array}{c}\mathrm{B}_{\mathrm{av}, \text { chem }} \\
(\mathrm{MW})\end{array}$ \\
\hline \hline $\mathrm{PS}$ & 4.83 & 5.10 \\
\hline $\mathrm{OS}$ & 4.97 & 5.58 \\
\hline $\mathrm{NS}$ & 5.76 & 6.01 \\
\hline
\end{tabular}

Assuming that the Natural State of the river stands for the maximum exergy potential $(100 \%)$, the present state represents its $84 \%$ and $85 \%$ for the potential and chemical component, respectively. The figures obtained for the Objective State are about $86 \%$ for the potential and $93 \%$ for the chemical.

On average, the exergy value of the Muga river, is about $5 \mathrm{MW}$ (potential) and $5 \mathrm{MW}$ (chemical) in the Present State (PS) of the river. It perfectly fits with the known data of the hydroelectricity power installed in the Boadella Dam (close to the river source), which is 3.6 MW.

In addition to that, looking at the monthly figures, it can be observed that the resulting power is higher in those months when the river flow is higher, as expected.

An additional interesting figure was obtained when these global exergy chemical values were compared with the power that is currently being used to clean the Muga river waters. In the Muga area, there are several waste water treatment plants; the most important, attending to its capacity, is the Figueres one. In the last stretch, the Peralada, the Castelló $d$ ' Empuries and the Empuriabrava WWTPs are located. The total power accounts for all those utilities and it is about $4 \mathrm{MW}$, almost the same as the calculated chemical exergy of the river.

Finally, the indexes related to the potential and chemical use of the river can be calculated by applying the definitions provided in Section 2.1. The input figures for the calculation are given in Table 4 . There, it can be seen that the current use of the potential component of the river is quantified in $3.6 \mathrm{MW}$ (from a total potential of 4.83 MW), while the technology able to take advantage of the 5.1 MW of chemical potential is just being born. Moreover, the exergy content of the residues within the water flow in the Muga river is $0.71 \mathrm{MW}$ and the fuel required to clean it is $3.92 \mathrm{MW}$. This last figure is calculated after analyzing the efficiency of the WWTPs running in the area.

Table 4. Index Refining the exergy value of the Muga river in its $P S$.

\begin{tabular}{|c||c||c||c||c||c||}
\hline $\mathrm{P}_{\text {pot }}$ & $\mathrm{P}_{\text {chem }}$ & $\mathrm{F}_{\text {pot }}$ & $\mathrm{F}_{\text {chem }}$ & $\mathrm{R}$ & $\mathrm{F}_{\mathrm{R}}$ \\
\hline \hline 3.60 & 0.00 & 4.83 & 5.10 & 0.71 & 3.92 \\
\hline
\end{tabular}

As a result, the potential of the river coming from the geopotential exergy is currently exploited at $75 \%$ of its capacity, according to the value of PURI indicated in Table 5. The chemical potential, as already explained, is not being used and, therefore, the CURI value is equal to zero.

Table 5. Index Refining the exergy value of the Muga river in its present state.

\begin{tabular}{||c||c|c|c||}
\hline \multicolumn{1}{|c||}{ Plant index } & \multicolumn{3}{|c|}{ Whole river indexes } \\
\hline \hline RTPI & PURI & CURI & $\mathrm{F}_{\mathrm{R}} \mathrm{RI}$ \\
\hline \hline 0.18 & 0.75 & 0.00 & 0.77 \\
\hline
\end{tabular}

The Residues in the Treatment Plant Index (RTPI) results 0.18 , which indicates that the water treatment plants within the watershed are working far from taking 
full profit of the exergy of these residues to clean up the river, or in other words, we need 5 times more exergy to get rid of these waste than its contained exergy. A technological objective for waste treatment plants could be to reach self-sufficiency. In other words, there is enough exergy of its organic waste to clean up the water.

Finally, the Fuel-Residues River Index $\left(F_{R} R I\right)$ indicates that the fuel required to eliminate the waste is about $77 \%$ of the chemical potential exergy of the water flowing through the Muga river. At this point, the comparison leads to think that the exergy required for maintaining the quality of the river water could be, in specific cases, even higher than the chemical potential of the stream.

\section{Conclusions}

The main thermodynamic value of a river comes, if no special thermal phenomena are detected, from its potential and chemical features. The global potential and chemical value of a water body can be given from a thermodynamic perspective attending to the evolution of them along time and space.

It has been explained along this work that it is possible to assess the exergy difference between two given states and, in this way, analyze how much of the potential of the river is being used.

The obtained figures give ideas about the exergy values of the considered river and allows its comparison with other parameters such as the power consumed by the currently installed waste water treatment plants along its course.

The potential exergy content in the water flow is given by $\mathrm{F}_{\text {pot }}$. It decreases as the elevation does, until the river mouth. The chemical potential is represented by $F_{c h}$, which gives idea about the amount of exergy dispersed into the sea although, as mentioned, it is used by the biodiversity in the shore.

In this paper, it has been shown the chemical value of a river is, from a thermodynamic perspective, as much as its potential value. Obtained values are both about $5 \mathrm{MW}$ for the Muga river. This result is quite interesting: the chemical value of the river is as much as its well-known and exploited potential value and must be taken into consideration for future studies.

An elementary and mistaken conclusion could however be obtained from our analysis: if our technology were able to take advantage of the chemical exergy potential of water at commercial scale, an energy source similar to hydropower could theoretically be developed. So let's develop it. However, if we would accept such a statement, it would mean that Nature is nothing but an inventory of resources for human purposes. Thus denying a wide-ranging perspective.

The important amount of chemical exergy that continuously goes into the sea in the river mouths constitute the natural irreversibility in the estuaries that maintain and develop the diversity of fauna and algae in those areas. That is, life exists because of that exergy and its associated irreversibility.

If our reflection after examining the numbers for $F_{\text {pot }}$ and $F_{c h}$ is limited to the idea of installing a huge forward osmosis plant in each water stream, we are losing the most important guideline: we are just a part of the ecosystem.
Our planet has plenty of resources and those resources are for life (in its most general sense), not only for the humans settled in the considered watershed. There is then, effectively, a hidden chemical value of water. It is far from being null and it is not a value for the future at expenses of the technological development. It is already a fundamental value that is being used by the biodiversity living in the estuaries, the richest places within the oceans.

All in all, Physical Hydronomics may help to bring up to light that hidden value of water flows, their chemical exergy.

\section{Acknowledgements}

The authors greatly acknowledge the financial support given to this paper, which is under the framework of the IDERE II R+D+I project (ENE2010-19834), financed by the Spanish Ministry of Education and Science and the Catalan Water Agency (ACA) for its support.

$\begin{array}{ll}\text { Nomenclature } \\ \text { B } & \text { Exergy } \\ \text { B } & \text { specific exergy } \\ \text { CURI: } & \text { Chemical Use of River Index } \\ \text { F } & \text { Fuel } \\ F_{R} & \text { Required fuel to eliminate the waste R } \\ \text { FO } & \text { Forward Osmosis } \\ \text { IM } & \text { Inorganic Matter } \\ \text { NS } & \text { Natural State } \\ \text { OM } & \text { Organic Matter } \\ \text { OS } & \text { Objective State } \\ \text { P } & \text { Product } \\ \text { PS } & \text { Present State } \\ \text { PURI } & \text { Potential Use of River Index } \\ \text { R } & \text { Residues/waste } \\ \text { WWTP } & \text { Waster Water Treatment Plant }\end{array}$

$\begin{array}{ll}\text { Subscripts } \\ \text { ch } & \text { chemical } \\ \text { pot } & \text { potential }\end{array}$

\section{References}

Botero, E. (2000). Valoración exergética de recursos naturales, minerales, agua y combustibles fósiles. Tesis doctoral. Departamento de Ingeniería Mecánica. Universidad de Zaragoza. [In Spanish].

Cath T.Y., Childress A.E., Elimelech M. (2006). Forward osmosis: Principles, applications, and recent developments. Journal of Membrane Science, 281 (12): 70-87.

Chen, G.Q. (2006). Scarcity of exergy and ecological evaluation based on embodied exergy. Nonlinear Science and Numerical Simulation 11, pp. 531-552. Elsevier.

Chen, G.Q. and Ji, X. (2007). Chemical exergy based evaluation of water quality. Ecological Modelling. Pp. 259-268. Elsevier.

CWA, Catalan Water Agency (2004). Recull de dades. Els recursos hidrics en regim natural a les conques internes de catalunya (1940-200). Agéncia Catalana de 1'Aigua. Generalitat de Catalunya, Departament de Medi Ambient i Habitatge. [In Catalan]. 
CWA, Catalan Water Agency (2008). Análisi Económica per a la planificació hidrológica. Catalunya: L'experiéncia pilot a la Conca de la Muga.Agéncia Catalana de l'Aigua.Generalitat de Catalunya. Departament de Medi Ambient i Habitatge. [In Catalan].

Delli Priscoli, J. (2000). Water and civilization: using history to reframe water policy debates and to build a new ecological realism. Water Policy, 1 (6) pp. 623636.

Gong, M. and Wall, G. (2001). On exergy and sustainable development, Part-2. Exergy, an International Journal 4, pp. 217-233. Elsevier.

IHA, 2008. The contribution of hydropower. Factsheets. International Hydropower Association. Available at: www.hydropower.org

Jørgensen, S.E. 2006. Eco - Exergy as Sustainability. WIT Press Southampton, Boston.

Le Goff, P. (1979) Énergétique industrielle: Analyse thermodynamique et mechanique des economies d'energie. Paris Technique et documentation.

Martínez, A. and Uche, J. (2010). Exergy of organic matter in a water flow, Energy 35 (1), pp. 77-84.

Martínez, A. (2009). Exergy costs assessment of water bodies: Physical Hydronomics, Ph.D Dissertation, University of Zaragoza. Spain.

Martínez, A; Uche, J; Valero, A. and Valero, Al. (2010). Environmental costs of a river watershed within the European water framework directive: Results from Physical Hydronomics. Energy, 35 (2), pp. 10081016.

New Scientist (electronic journal): Available at: http://www.newscientist.com. Last access: October 2011.

Nordic Council of Ministers. Nordic Energy Solutions website. Available at: www.nordicenergysolutions.org Last access: October 2011.
Szargut,J.; Morris, D.R; and Steward, F.R. (1988). Exergy analysis of thermal, chemical and metallurgical processes. New York: Hemisphere.

Valero, A. (1998). Thermoeconomics as a conceptual basis for energy ecological analysis. Proceedings of the $1^{\text {st }}$ International workshop Advances in Energy Studies. Pp. 415-444. SG Editoriali Padova.

Valero, A., et al. (2009). Physical Hydronomics: Application of the exergy analysis to the assessment of environmental costs of water bodies. The case of the inland basins of Catalonia. Energy 34 (12), pp. 21012107.

Valero, A.; Lozano, M.A. and Muñoz, M. (1986). A general theory of exergy saving, I, II and III. Computed Aided Engineering and Energy Systems: Second Law Analysis and Modelling, AES. Vol 2-3 Vol. 2-3, ASME Book H0341C. New York.

Valero, A; Uche, J; Valero, Al; Martínez, A; Naredo, J. and Escriu, J. (2009). The Fundamentals of Physical Hydronomics: a novel approach for physico-chemical water valuation. In "Water, Agriculture, and Sustainable Well-Being" Chapter 5, pp. 97-118. Oxford University Press.

Ventura, M.; Ribas, A. and Sauri, D. (2000). Gestión del agua y conflictividad social en la Cuenca del Río Muga. Geographicalia, 38 pp. 55-70. [In Spanish].

Wall, G. (1986). Exergy -A useful concept. Physical Resource Theory Group. Chalmers Bibliot. Trick. University of Technology, Göteborg, Sweden 3,4 EOLSS Publisher.

WEC, World Energy Council (2007). Survey of Energy Resources 2007. World Energy Council.

Zaleta-Aguilar, A.; Ranz, L. and Valero, A. (1998). Towards a Unified measure of renewable resources availability: The exergy method applied to the water of a river. Energy Conversion Management, 39 (1618): 1911-1917. 